\title{
Fin de Mundo: Neruda Entre la Angustia y la Esperanza
}

Aunque toda la poesía de Pablo Neruda, en su ya larga trayectoria, se desarrolla en base al contraste entre la preocupación y el optimismo, la angustia y la esperanza, en la producción sucesiva al Mentorial de Isla Negra (1964) y. casi en vísperas del Premio Nobel, un libro adquiere significado particular por el hecho de acentuarse este dualismo: Fin de mundo.

Aparecida en 1969, la obra se sitúa dentro de un momento de intensa actividad creativa; la preceden, en efecto, seis libros, Arte de pajaros (1966), Una casa en la arena (1967), Fulgor y muerte de Jadquin Murieta (1966), La barcarola (1967), Las manos del dia (1968), Aün (1969), y la siguen, hasta la fecha, otros tres, Las piedras del cielo (1970), La espada encendida (1970), Geografía inconclusa (1972).

En medio de todos estos libros de poesía, prosa, teatro, Fin de mundo destaca más hondamente la fundamental preocupación nerudiana por el destino del hombre. El título mismo, que significa propiamente no el fin del mundo sino la víspera de este fin, expresa claramente la participación angustiada del poeta en la condición dramática de la humanidad, la conciencia de estar frente a un momento decisivo de su futuro.

Más de una vez Neruda ha declarado el origen de su poesía, el significado que ella tiene como participación en la lucha del hombre. Con ocasión del Premio Nobel, en su discurso de agradecimiento, él confirma una vez más el significado que atribuye a su condición de poeta:

Yo escogí el difícil camino de una responsabilidad compartida $y$, antes que reiterar la adoración hacia el individuo como sol central del sistema, preferí entregar con humildad mi servicio a un considerable ejército que a trechos puede equivocarse, pero que 
camina sin descanso y avanza cada día enfrentándose tanto a los anacrónicos recalcitrantes como a los infatuados impacientes. Porque creo que mis deberes de poeta no sólo me indicaban la fraternidad con la rosa y la simetría, con el exaltado amor y con la nostalgia infinita, sino también con las ásperas tareas humanas que incorporé a mi poesía. ${ }^{1}$

Fin de mundo interpreta concretamente la posición nerudiana, que se identifica con el destino de la humanidad. En el pasaje citado del discurso Nobel existe una significativa alusión a las posibles equivocaciones populares, y en ellas a las del poeta en cuanto parte del pueblo. Es un problema que viene atormentando directamente a Neruda desde tiempo y al que concretamente hace referencia también en Fin de mundo, cuando se declara asaltado por un improviso "concurso de tinieblas", que parece poner en duda muchas cosas, destacar los errores del mismo poeta, errores de perspectiva en la individuación de los hombres del bien. ${ }^{2}$ El recuerdo de los versos dedicados a Stalin no deja de atormentar a Neruda y con insistencia él vuelve sobre el argumento, a partir del Memorial de Isla N'egra.9 No se trata de un artero pretexto para rescatar una moralidad que siente comprometida, a través de la justificación humana del error, porque, como en tiempos pasados el poeta tuvo el valor de denunciar su cansancio frente a la piedra, a los "burros de la energía", ${ }^{4}$ de reivindicar para sí mismo la libertad de vivir íntimamente, ${ }^{5}$ y para el hombre de ponerle nombre a las cosas, ${ }^{6}$ en Fin de mundo proclama abiertamente su rechazo por las "caras sin sonrisa", los "terribles retratos", los hombres, en fin, que como Stalin o Mao se le presentan como esclavizadores de las multitudes, a las que con su propio culto personal imponen una concepción prefabricada del mundo. ${ }^{7}$

En Fin de mundo el hombre aparece oprimido por una atmósfera irrespirable y sombría, rodeado de señales tertibles que anuncian su destrucción próxima y, como ya en la primera Residencia en la tierra, ${ }^{8}$ más que un ser poderoso es un vencido, en poder de la muerte. Frente a esta dramática situación, Neruda reacciona insistiendo una vez más

1 Cf. Discurso de Estockolm (Alpignano: Tallone, 1972).

2 Fin de mundo (Buenos Aires: Losada, 1969), "La pasión".

3 Memorial de Isla Negra (Buenos Aires: Losada, 1964), V-Sonata crítica: "El episodio".

4 Estravagario (Buenos Aires: Losada, 1958), "Cierto cansancio".

5 Ibid., "Pido silencio".

"Ibid., "Cierto cansancio".

"Fin de mundo, ob. cit., "El culto".

\& Residencia en la tierra - I, "Entierro en el Este". 
en la irremediabilidad de un cambio, alienta la esperanza, razón de su poesía. En el mismo discurso Nobel, aludiendo a un verso de Rimbaud, "A l'aurore, armés d'une ardente patience, nous entrerons aux splendides Villes", confirma de nuevo su fe en el hombre y la persistencia de una perspectiva final positiva, ${ }^{9}$ ya en tantas ocasiones expresada.

Fin de mundo vive, pues, entre perspectivas de catástrofe y la persistencia de una fe en la salvación de la humanidad. El poeta expresa en un verso su función fundamental en el mundo: "Mi deber es vivir, morir, vivir."10 La explicación de este verso la dio él mismo: participando de la vida del hombre el poeta vive y muere con él, pero vuelve a vivir, porque existe el "hombre infinito" $y$, a pesar de las muchas muertes individuales, él no acaba; deber del poeta es, pues, seguir infundiéndole la esperanza.11

En el libro poético de que tratamos, Neruda nos muestra la cara más negativa de la realidad actual; las ilusiones, siempre numerosas, se deshacen en la desilusión, porque el mal parece infectar tenazmente los tímidos brotes del bien. El poeta observa con angustia las cosas, interpreta el mensaje negativo de una edad en la que las perspectivas felices se hunden progresivamente en la tristeza. Las grandes esperanzas que la humanidad había puesto en el futuro al terminar la segunda guerra mundial, han fracasado. A la era de paz y hermandad esperada se ha impuesto una de guerra y traiciones. La muerte del "Ché", la desaparición de los "leaders" de la independencia africana, la larga y espantosa guerra de Viet Nam, los trágicos acontecimientos de Praga, obscurecen el significado positivo de hechos como el triunfo de la revolución cubana. Todo ello es fruto de una paz que brotó de una tremenda violencia; la primera bomba atómica sobre el Japón. Precisamente de esto, según Neruda, se origina el trastorno del mundo. De la "usina total de la muerte", del "núcleo desencadenado" sale la gran amenaza para el futuro, que llevará al suicidio del universo. ${ }^{12} \mathrm{El}$ observa con angustia al hombre que procrea en el tormento y vive en la perspectiva de ser destruido por la bomba, devorado por mandíbulas de máquinas feroces, aplastado por un tanque. La maquinaria despiadada y cruel es el nuevo símbolo de la edad infeliz que vivimos. La eficiencia aparente del mundo, mito engañoso de la sociedad moderna, es causa de agotamiento de las cualidades humanas, motivo de infelicidad y muerte.

9 Discurso de Estockolm, ob. cit.

to Fin de mundo, ob. cit., "La puerta".

11 Conferencia en Milán (10 de marzo, 1972).

12 Cf. Fin de mundo, ob. cit., "Bomba (I)". 
Intimamente implicado en la vida del hombre, el poeta observa con dolorida participación el fin miserable del siglo. Ya la naturaleza es un bien perdido; la inocencia está sometida al martirio, los niños sucumben sin culpa en la recurrente enfermedad de la guerra; los bienes supremos se pierden definitivamente. La muerte vuelve a ser una presencia dominadora que acentúa el desgarrado sentimiento de orfandad, que domina a la criatura frente al fracaso de los mitos en que había creído y la ausencia evidente de Dios, una vez más denunciada por Neru$\mathrm{da}$. La muerte preside así las perspectivas humanas en la aberración de la guerra. Los objetos atestiguan trágicamente la crueldad y la gratuidad de la muerte misma: el sombrero caído, el zapato quemado, el montón "póstumo" de anteojos, el hombre, la mujer, la ciudad vueltos ceni$z a$, denuncian la locura de un siglo cruel, que se destruye fabricando y empleando las armas de la muerte. ${ }^{13}$

En la enumeración patética de los objetos, en la alusión a los cuerpos inanimados, a las construcciones humanas, lábiles y vanas ante la furia destructora, la participación nerudiana a nuestro drama se manifiesta en toda su profundidad y desgarrada ternura. En su visión amarga del mundo el poeta acude a símbolos de larga tradición negativa en su poesía, actuando en ellos una variación semántica de signo positivo. Es el caso de los "anteojos", que siempre significaron en la poesía de Neruda lo repulsivo de la vida $y$, al contrario, en Fin de mundo expresan la trágica fragilidad de la naturaleza humana, desamparada ante el ataque de la guerra. Lo mismo dígase de "zapatos", "sombrero", "ceniza". En un proceso eficaz de desrealización de lo real, "ceniza" vuelve al significado de "ceniza celeste", que ya había aparecido en Estravagario,"1/ al considerar la inhumana destrucción de seres y ciudades. Pero, lo que en Fin de mundo representa con mayor eficacia la condición desamparada del hombre ante la injusticia y la crueldad de la guerra, es la mención del juguete que sobrevive a la desaparición de la criatura inocente que lo tuvo entre sus brazos; la "muñeca" del Asia, abandonada por la niña que vanamente intentó escapar a la muerte, que la esperaba bajo los muros en llamas de su casa o en el refugio vano de los arrozales. Las cuen. cas vacías del juguete representan una denuncia durísima, que arranca su fuerza de una zona amplia del sentimiento:

Muñeca del Asia quemada por los aéreos asesinos,

13 Ibid., "Las guerras".

14 Estravagario, ob. cit., "No me hagan caso". 
presenta tus ojos vacíos

sin la criatura de la niña

que te abandonó cuando ardía

bajo los muros incendiados

o en la muerte del arrozal.15

La imagen del fuego destruyendo al hombre tiene larga tradición en la poesía de Neruda, y su origen está en la primera experiencia asiática del poeta. ${ }^{16}$ En el Memorial de Isla Negra, el poeta afirmó que si algo había aprendido en su vida lo debía a esta experiencia de muerte; ${ }^{17}$ pero en Fin de mundo la imagen asume un significado más trágico por la inocente protagonista. El recuerdo del ser humano destruido se hace más desgarrador a través de la mención de los objetos sobre los que se fundó su vida mínima. Borges también, en su poesía, contempla ${ }^{18}$ en la muerte del hombre los objetos que quedan, interpretándolos como "menudas sabidurías" que sobreviven a la desaparición de la criatura; de ellas se origina una honda nota de melancolía. La posición de Ne. ruda, sin embargo, es distinta de la del poeta argentino - y ello ya desde las Residencias - debido a una participación más directa en el drama del hombre: al sentimiento de dolor por los desaparecidos se añade la denuncia concreta de la injusticia que significa el ataque cruel de la muerte en su aspecto más criminal. La constatación súbita y amarga de la desaparición de los amigos alrededor de la mesa en los Cantos ceremoniales, ${ }^{19}$ se repite en Fin de mundo. De la humanidad perseguida, atormentada, humillada, Neruda representa en el libro la nota más doliente. Como ya en "Walking around", la ropa colgada de un alambre goteaba "lentas lágrimas sucias", ${ }^{20}$ en Fin de mundo ella denuncia la miserable condición del hombre en su ausencia:

recuerdo las piernas que faltan, los brazos que no las llenaron, partes sexuales humilladas y corazones demolidos. ${ }^{21}$

\footnotetext{
15 Fin de mundo, ob. cit., "Las guerras".

16 Residencia en la tierra - $I$, "Entierro en el Este".

17 Memorial de Isla Negra, ob. cit., II, La luna en el laberinto: "Aquellas vidas".

${ }_{18}$ Cf. J. L. Borges, Oby a Poética (Buenos Aires: Emecé, 1964), "Ia noche que en el Sur lo velaron".

19 Cantos ceremonicles (Buenos Aires: Losada, 1961), "Fin de fiesta".

20 Residencia en la tierra - II, "Walking around".

21 Fin de mundo, ob. cit., "Las guerras".
} 
La denuncia nerudiana va continuamente de lo externo a lo interno. La consideración de la triste condición en la que vive el hombre acentúa en el poeta la conciencia de una culpa personal, que consiste en el hecho de haber seguido viviendo "cuando mataban a los otros" y haberle acaso robado la vida a quien era mejor: "Tal vez les robamos la vida / a nuestros hermanos mejores". 22

Con estas consideraciones, estos angustiosos problemas, Fin de mundo se presenta cual nuevo capítulo de aquel hombre "claro y confundido", "enérgico y otoñabundo", "lluvioso", pero no ya "alegre" que es, según sus propias expresiones, ${ }^{23}$ Pablo Neruda. El ostentado prosaísmo del lenguaje, en este libro poético, representa, con el intento evidente de resistir las sugestiones líricas - propósito pocas veces logrado-, la honda preocupación del poeta, metido en materia tan quemante. Neruda ha llegado a un momento decisivo de su vida, en el cual se impone un balance de la existencia. Esto implica necesariamente un juicio sobre el tiempo en que al poeta le ha tocado vivir. El se siente más que nunca parte integrante de este momento histórico, y si el siglo se le presenta "tristísimo", si las negaciones van acumulándose en la cuenta final - "Yo conté las manos cortadas / y las montañas de ceniza / y los cabellos sin cabeza" - ${ }^{24}$ nada rechaza de su experiencia personal: la del dolor como la del sentimiento, las notas íntimas que hicieron palpitar su alma y su verso, las linfas fortalecedoras del pasado, las raíces y la hojarasca que le enseñaron, entendiendo la tierra, a entenderse a sí mismo, a "volar más alto". ${ }^{25}$ Tampoco rechaza el hecho de haber "paseado de rama en rama", ${ }^{28}$ el haber identificado sus ojos con las hojas, y al final, no haber aprendido nada definitivo; ${ }^{27}$ ni la experiencia del exilio, el haber amado hondamente al hombre a través de tantas manifestaciones de injusticia y de muerte, o el haber pasado por la cruel experiencia de la guerra civil española, ("España de mis dolores".) ${ }^{28}$ A pesar de lo cual Neruda afirma que todo acabó por dar un significado a su vida, haciéndolo testigo del tiempo, intérprete angustiado del siglo. Y lo que el poeta siente más es el no haber encontrado respuesta a los inquietantes interrogativos que dominaron su vida, el no haber alcanzado la razón verdadera de las cosas: "Por qué tantas cosas pasaron / y por qué no pasaron otras?"29

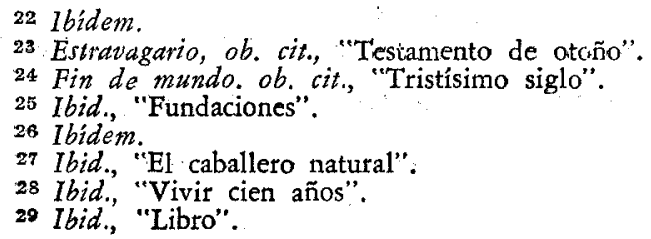


La problemática neiudiana gira continuamente en torno al por qué del hombre y del mundo. El mar, símbolo de la eternidad del tiempo $y$ de su indiferencia ante el transcurso humano, ${ }^{30}$ vuelve en Fin de mundo a reconocer al poeta, pero sin aclararle, con su fría lección, el mis. terio de la vida, sin abrirse a ninguna respuesta concreta. ${ }^{31}$ "Heroico y simultáneo", el mar no explica la complicada índole de los acontecimientos, permanece únicamente testigo de sangre y de tormento. ${ }^{82}$

Debido a esta nunca satisfecha ansia de conocimiento Neruda vuelve con más ahinco a afirmar la razón inevitable y el significado de su canto. Frente al abandono del hombre, a la soledad que lo rodea, el poeta debe enarbolar la bandera de la esperanza, sin por ello creerse superior a los demás, sino más bien humillándose en un sentimiento de culpa por la inevitable complicidad con la fuente del mal:

Para los pueblos fue mi canto

escrito en la zona del mar

y viví entre el mar y los pueblos

como un centinela secreto

que defendía sus batallas

lleno de amor y de rumor:

porque soy el hombre sonoro,

testigo de las esperanzas

en este siglo asesinado.

Cómplice de la humanidad

con mis hermanos asesinos. ${ }^{33}$

Fin de mundo concluye con una fecha, 1970, y una perspectiva de otros treinta años inciertos. En Neruda permanece la duda en torno a su esencia, si serán "flores" o bien "fuego", si para el hombre se reservarán cosas positivas o negativas. ${ }^{34}$ Pero, por encima de angustias y dudas, vuelve a afirmar su deber hacia la humanidad, el de establecer la nueva ternura en el mundo $y$, por sobre el crepúsculo del siglo, afirmar la permanencia del "hombre infinito", el inevitable triunfo de la felicidad. ${ }^{35}$ El verso con que termina el libro - suerte de extenso poema en varios cantos- nos lleva significativamente a la tierra, madre

\footnotetext{
so Estravagario, ob. cit., "Desconocidos en la orilla".

31 Fin de mundo, ob. cit., "Tristísimo siglo".

82 Ibid., "El mar".

33 Ibid., "Canto".

34 Ibidem.

35 Ibidem.
} 
engendradora y protectora; y el panteísmo nerudiano, una vez más afirma la permanencia del mundo. ${ }^{36}$

A pesar del acento preocupado que domina el poemario que examinamos, Pablo Neruda queda fundamentalmente como el poeta de la vida, por encima de las constataciones de muerte; de la fe en el porvenir, por sobre la desilusión y el desaliento. Estos versos, en los que se reflejan con tanta angustia las oscuras e inquietantes perspectivas de nuestro tiempo, dan a la poesía nerudiana una nueva dimensión humana, que se afirma sobre un fondo permanente. Los tristes presagios, las inciertas realidades, se transforman, casi por contraste, obstinadamente, en fuentes inagotables de la esperanza.

Exaltador del hombre en su significado más grande, del hombre quẹ en otra época definió "más grande que el mar y que sus islas", ${ }^{37}$ Neruda tiene la exacta conciencia de que abandonarlo a sí mismo, dejarlo sumergirse en el desaliento, seria traicionarle, faltar a su propia misión. Si el mal es la sustancia diabólica del siglo, que la humanidad no vivió, tanto deseaba vivirlo, deber del poeta es seguir indicando "otros caminos incesantes", ${ }^{38}$ en realidad siempre los mismos, alientos al futuro, hacia la hermandad y la justicia.

Universidad de Venecia

GIUSEPPE BELLINI

36 Ibid., "Adiós".

37 Canto general, "Alturas de Macchu Picchu, XI".

38 Fin de mundo, ob. cit., "La pasión". 